\title{
Preface to Special Column on New Porous Catalytic Materials
}

Over the last 15-20 years a wide range of new porous catalytic materials has been discovered in the wake of major developments in mesostructured materials and hybrid porous solids such as metal organic frameworks (MOFs). These two developments have both enormous potential to produce catalyst supports and solids. It may be argued that most existing industrial catalysts may be revisited for improvement taking advantage of the novel materials. In both cases new techniques allow controlling not only specific surface area and pore volume but even more importantly pore size distribution and therefore the diffusional properties of reactants and products. These are especially critical when dealing with large molecule reactants as frequently encountered and converting natural products. Both subfields are indeed yielding on a regular basis creative original materials which generate new catalysts, sometimes unexpectedly rejuvenating mature catalytic technologies. This special column is intended to illustrate these current efforts which for a large part are occurring in the Chinese catalysis community. The editors come from Canada and China, and the authors involve well-known researchers from Canada, Sweden, Korea, Taiwan Province and Mainland China. This column contains two review articles, one communication and seven original research articles.

The two reviews deal with complementary industrial processes: the synthesis of ethylbenzene and its oxidative dehydrogenation to monostyrene. A complete historical review of this significant process is made with particular emphasis on recent industrial developments in China (Weimin Yang et al.). The discussion indicates how the recently developed mesoporous zeolite MCM-22 yields systematically enhanced activity compared to conventional MCM-22. Conversion to monostyrene using $\mathrm{CO}_{2}$ as a mild oxidizing agent in ethylbenzene dehydrogenation is then reviewed. The catalysts are $\mathrm{ZrO}_{2}-\mathrm{TiO}_{2}$ mixed oxides also prepared by a sol-gel technique (Sang-Eon Park et al.).

Hard templating using KIT- 6 silica as the template was used to generate high specific surface area mesostructured $\mathrm{MnO}_{2}$. This was shown to be an especially active oxidation catalyst able to convert traces (400 ppm) of formaldehyde at tempera- ture lower than $130{ }^{\circ} \mathrm{C}$ (Junhua Li et al.). Similarly mesostructured perovskites $\left(\mathrm{LaMnO}_{3}, \mathrm{LaCoO}_{3}, \mathrm{LaNiO}_{3}\right)$ were prepared by a slightly different hard templating method and tested in the

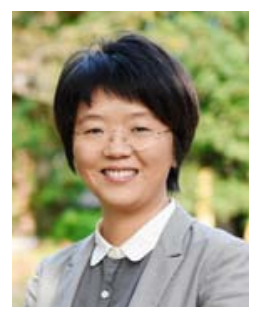

Prof. Ying Wan (Guest Editor)

The Education Ministry Key Lab of Resource Chemistry, Shanghai Key Laboratory of Rare Earth Functional Materials, and Department of Chemistry, Shanghai Normal University

E-mail: ywan@shnu.edu.cn

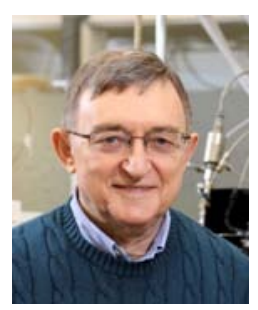

Prof. Serge Kaliaguine (Guest Editor)

Department of Chemical Engineering, Université Laval, Quebec City, G1V 0A6, Canada E-mail: Serge.Kaliaguine@gch.ulaval.ca

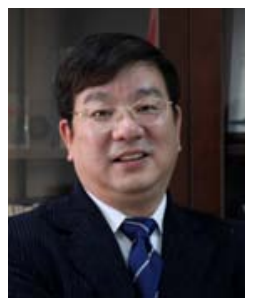

Prof. Dongyuan Zhao (Guest Editor) Laboratory of Advanced Materials, Department of Chemistry,

Fudan University

E-mail: dyzhao@fudan.edu.cn 
catalytic oxidation of traces of methanol (Serge Kaliaguine et al.). Mesostructured $\mathrm{LaMnO}_{3}$ was the object of a detailed kinetic study in this reaction.

Mesostructured $\mathrm{MO}_{x}-\mathrm{Al}_{2} \mathrm{O}_{3}$ catalysts $(\mathrm{M}=\mathrm{Mn}, \mathrm{Fe}, \mathrm{Co}, \mathrm{Ni}, \mathrm{Cu}$, $\mathrm{Ba}$ ) prepared by a one-pot technique were compared with mesostructured $\mathrm{Al}_{2} \mathrm{O}_{3}$ as supports for nanoparticles of $\mathrm{Rh}_{2} \mathrm{O}_{3}$. The resulting materials were found active for $\mathrm{CO}$ oxidation and $\mathrm{N}_{2} \mathrm{O}$ decomposition (Zhen Ma et al.).

Porous $\mathrm{CeO}_{2}$ nanotubes were prepared by a hydrothermal synthesis using the commercial triblock copolymer P123 as a soft template. These were then used as a support for Pd particles. The resulting catalysts showed to be highly active in $\mathrm{CO}$ oxidation (Jinlong Gong et al.).

Other articles dealt with using a variety of original supports for supported metal catalysts. These were first prepared by a one-pot synthesis of a hybrid mesostructured gold containing phenolic resin $/ \mathrm{SiO}_{2}$ combination, yielding $\mathrm{Au} / \mathrm{msC}$ after calcination and silica removal. The mercaptopropyl moiety of MPTMS added to TEOS allowed grafting of $\mathrm{Au}$ in the hybrid precursor and reaching a good control of gold particle size (Ying Wan and Osamu Terasaki et al.).

Ordered mesoporous carbon was also used as a support for particles of Pt alloyed with $\mathrm{Ru}, \mathrm{Fe}$ or Mo. This support was prepared by a hard templating approach using SBA-15 silica as the template. The resulting solids were used as electro-cata- lysts in the electro-oxidation of methanol, showing interesting properties in terms of current density, onset and peak potential, and forward vs reverse anodic peak current ratio in a cyclic voltammetry test. The electro-catalysts also showed resistance to coke formation and to deactivation by CO (Shang-Bin Liu et al.).

One problem in designing heterogeneous catalysts for $\mathrm{C}-\mathrm{C}$ coupling reactions such as Suzuki, Heck or Sonogashira reactions is the stability of the support under basic conditions. A series of Pd-metalated porous organic polymers containing phenanthroline ligands exhited high activity and recyclability in all three coupling reactions (Feng-Shou Xiao et al.).

$\mathrm{Ni@Pd} \mathrm{core/shell} \mathrm{nanoparticles} \mathrm{were} \mathrm{prepared} \mathrm{by} \mathrm{sol-}$ vo-thermal reduction of bivalent nickel and palladium in oleylamine and triethylphosphine. These were then deposited in the MOF framework MIL-101 by wet impregnation in $n$-hexane. Exceptional performances were obtained in the catalytic hydrogenation of nitrobenzene as an example of hydrogenation of substituted nitroarene reactions (Yingwei Li et al.).

All authors ought to be congratulated for the high quality of their contributions in this vast area of modern research, showing exciting possibilities for the future of industrial catalysts development. This special column in Chinese Journal of Catalysis would also benefit the further internationality and improvement of catalysis and community in China. 